\title{
Carbon Emissions Determinants and Forecasting: Evidence from G6 Countries
}

\begin{abstract}
We examine the explanatory and forecasting power of economic growth, financial development, trade openness and FDI for $\mathrm{CO}_{2}$ emissions in major developed economies within the context of the debate on curbing $\mathrm{CO}_{2}$ emissions Post-Paris Agreement (COP21). Using data from G-6 countries from 1978 to 2014 and employing a set of empirical approaches, we find weak evidence of the Environmental Kuznets Curve, while economic growth, capital market expansion, and trade openness are found to be major drivers of carbon emissions. Carbon emissions are also weakly and negatively affected by stock market capitalisation and FDI. Moreover, the forecasting performance is quite good, particularly by augmenting the model with energy consumption and oil prices. With respect to climate commitments, our empirical findings reveal important policy implications.
\end{abstract}

Keywords: GHG emissions; Determinants; Forecasting; Paris Agreement COP21.

JEL Classifications : C51, C53, E22, Q43, Q56 


\section{Introduction}

To combat the existential threats of climate change posed by the GHG emissions in the $21^{\text {st }}$ century, 195 nations and sovereignties participated in the Paris global climate deal (COP21) agreed in December 2015. The Paris Agreement entailed a global plan of actions which was put in place with a target that by the end of the $21^{\text {st }}$ century, the global warming could be restricted to $2^{\circ} \mathrm{C}$ compared to pre-industrial levels (Tol, 2015; Shahbaz et al., 2020). Although a critical assessment of the Paris COP21 by Morgan (2016) questioned the likelihood of success based on early trends and Nationally Determined Contributions (NDCs), the element of global consensus is unfortunately ended by the recent change of direction by the United States. Despite the ratification of the agreement by the large economies and emitters including China and the European Union, the United States declared to withdraw from the Paris accord. Considering the fact that the United States is one of the largest economies and a producer as well as a consumer of oil and petroleum products, its policy towards climate change can have serious implications and consequences (Shahbaz et al., 2020). As it stands, the United States contributes to around $16 \%$ of world GHG emissions. Besides, the other developed economies and particularly the members of $\mathrm{G} 7$ are also among the largest emitters of GHGs, including carbon dioxide $\left(\mathrm{CO}_{2}\right)$ emissions. For instance, the United States, Japan, Germany and Canada have higher per capita GHG emissions than the OECD average of 8.3 tons per capita (Climate Transparency, 2019).

The statistics on the $\mathrm{CO}_{2}$ emissions related to energy consumption suggest an increase of over 100\% from 15.51 gigaton in the year 1975 to 32.53 gigaton in the year 2017 (IEA, 2019). Concomitantly, this upsurge in global $\mathrm{CO}_{2}$ emissions led by rising energy consumption to meet intensified economic needs is the cause of great concern. The surging $\mathrm{CO}_{2}$ emissions levels have also exposed the world to the threat of existential challenges in the form of global warming and climate change. Undoubtedly, global warming is predominantly caused by GHG emissions due to extensive consumption and dependence on fossil energy sources to fuel economic development (Chiu, 2017). The findings of a report compiled by the Intergovernmental Panel on Climate Change (IPCC, 2014) showed that $\mathrm{CO}_{2}$ emissions themselves account for approximately $78 \%$ of GHG emissions, which is detrimental to the environment. If we look at energy-related emissions in the last few years, there is a sharp increase almost every year, except the year of the global financial crisis 2008-09 (see IEA, 2019). 
To the extent that the G7 countries are among the largest economies in terms of their economic size, financial sector, trade openness and attractive destinations of FDI as well as the most politically influential countries, our study focuses on their environmental impact on the global scale. In particular, we attempt to empirically investigate the dynamic patterns of their carbon emissions and the factors influencing their emissions. Our main contributions are therefore threefold. First, we propose a comprehensive approach to examine the explanatory power of important economic factors (economic growth, financial development, international trade openness, and FDI) in determining carbon emissions in the G6 countries (excluding Germany as this country does not have unified dataset before 1991). Our argument, which reinforces past studies, is that economic and financial development as well as FDI and trading relations of these countries have significant ecological consequences. The robustness of our empirical findings is also explored thoroughly by using a set of econometric approaches. Second, we attempt to forecast carbon emissions of the underlying countries based on their identified determinants. This forecasting exercise is important as it facilitates the formulation of forward-looking public policies to tackle climate change. To the best of our knowledge, this is the first study to investigate how the underlying factors affect forecasting the amount of carbon emission in these economies. Third, our study contextualises the debate on financial development and its ecological consequences for the case of six most advanced economies (G6) in the world, which have been a focus of many studies over the last two decades and whose policy lessons could be used for emerging and developing economies in their path of development. Looking at the environmental degradation in these important countries sheds light on how they committed to environmental preservation and protection. The choice of sample countries is equally motivated by the fact that they have well developed financial sectors, are widely open to international trade, and maintain a higher level of attractiveness for foreign direct investment. Moreover, within the G6 economies, the United States, Japan and Canada are among the top $\mathrm{CO}_{2}$ emitters.

Drawing and contextualising on the existing evidence, we briefly review the nexus between emissions and its potential four determinants including, growth, financial development, FDI and trade openness. A reasonable rate of economic growth is one of the core objectives of economic policymaking. However, the economic growth has environmental implications and the future economic growth may come at the cost of environmental degradation in the G6 countries which already have quite high levels 
of aggregate GHG emissions. The growth-emissions nexus is often seen through the lens of Environmental Kuznets Curve (EKC) showing an inverted U-shaped association between the growth of an economy and the degradation of its environment. There is also a clear distinction between the shortterm vs. long-term implications of economic development and growth. Though not always, but very often it is postulated that the economic growth can improve the environmental quality in the long-run and the environmental degradation is only a short-run issue. As the countries achieve higher income levels, economic growth starts to play rather a positive role in environmental improvement. Since the seminal studies by Grossman and Krueger (1991) and Shafik (1994) which theorised and provided foundations to the EKC framework, a number of empirical studies focusing on EKC have reported contrasting results across both individual country and group of countries samples (e.g., Onafowora and Owoye, 2014; Baek, 2015; Apergis, 2016; Al-Mulali and Ozturk, 2016; Özokcu and Özdemir, 2017; Shahbaz et al., 2018; Nasir et al., 2019; Pham et al., 2020). For instance, Shahbaz et al. (2018) argued that the presence of EKC depends on the development stage of a country. Similarly, a study by Özokcu and Özdemir (2017) on 26 OECD and 52 developing economies and Caviglia-Harris et al. (2009) on 40 selected economies found no significant evidence of EKC. In a recent survey of literate on ECK, Shahbaz and Sinha (2019) showed that the inconclusive evidence on EKC depends on contextual factors including the choice of explanatory variables, the time horizon of study and underlying approach to empirical estimation EKC relationship. Therefore, it is cogent to conduct an investigation, specifically focusing on the subject economies before drawing any inference on the growth-environment nexus.

Parallel to economic growth, the degree of financial development may have an important impact on the environment (e.g., Yuan and Gallagher, 2018; Leimbach et al., 2018; Campiglio, 2016). Zhang (2001) noted that the nexus between finance and emissions is manifested in the finance-led energy consumption according to which financial development leads to i) an increase in FDI inflows and economic growth which drives up energy consumption; ii) an increased usage of energy-intensive equipment and services, and iii) more investment which requires increased energy consumption. There is also a silver lining to the finance-environment nexus as the financial development can harbour new opportunities for renewable energy generation and allocation of finance to more innovative and efficient firms (Chang, 2015). Reconsidering the environmental effects of financial development is important 
because the evidence on the finance-environment is inconclusive (e.g., Nasir et al., 2019; Salahuddin et al., 2018; Shahbaz et al., 2016; Javid and Sharif, 2016; Charfeddine and Khediri, 2016; Omri et al., 2015; Ozturk and Acaravci, 2013; Çoban and Topcu, 2013; Tamazian and Rao, 2010; Tamazian et al., 2009 ) which could be due to the different channels of financial development as well as their differing importance in the subject economies. Concomitantly, the contrasting evidence is intriguing and provides the rationale for further research. Nonetheless, it is also vital to consider various aspects of financial sector rather focusing on a single measure of financialisation (Nasir et al., 2019). Compared to previous studies, we take a more inclusive approach to gauge the aspect of financial development. In so doing, we also use the issuance of debt and the expansion of the equity market, in addition to the domestic credit creation.

The literature also pays close attention to the role of FDI inflows as they can affect the environmental quality through economic growth. This makes it a crucial factor for estimating and forecasting the GHGs as a result of increased economic activity. It is worth noting that the G6 economies are major attractions for the global FDI. In theory, three dimensions of the FDI-environment nexus are hypothesised as the pollution-haven, the pollution-halo and the scale-effect hypothesis. When a host country with weak regulatory environment attracts FDI which causes environmental degradation, the pollution-haven hypothesis (PHH) supposed to prevail (Cole and Fredriksson, 2009; Naughton, 2014). By contrast, the pollution-halo hypothesis prevails in a scenario where the multinational and transnational firms bring FDI together with green technology as well as global environmental standards and practices to the host country. Finally, the scale-effect hypothesis posits that the FDI inflows lead to a surge in the host country's industrial output which in turn causes increased pollution and degradation of the environment (Rezza, 2013; Pao and Tsai, 2011). The empirical literature on the role of FDI suggests mixed and contrasting results. Studies finding positive repercussions of FDI on environmental quality include, among others, Pao and Tsai (2011), Al-Mulali and Tang (2013), Liu et al. (2017), and Jiang et al. (2017). By contrast, the evidence of increased GHGs emission as a result of FDI flows is provided in Ren et al. (2014), Tang and Tan (2015), Shahbaz et al. (2015), Paramati et al. (2016), Abdouli and Hammami (2017), Shahbaz et al. (2018) and Nasir et al. (2019). A few other studies obtain insignificant and inconclusive results (e.g., Kivyiro and Arminen, 2014; Lee, 2013; Baek, 2015; Zhu et 
al., 2016). Note also that along with the FDI, these studies often consider other factors, such as the economic growth, financial development and trade to have a more inclusive view of the GHGs dynamics. In a nutshell, the existing evidence seems to conclude that nexus between FDI and environment depends upon that fact that which channel is more dominant.

In a globalised world, the degree of trade openness is critical to economic growth and prosperity of a country. Since the G6 economies are major players in international trade, the growth-trade nexus is thus likely to have crucial ecological implications. In addition, a number of studies suggest that while the trade openness leads to enhance economic growth, it also comes at the cost of higher GHG emissions (e.g., Antweiler et al., 2001; McAusland, 2008; Shahbaz et al., 2015; Ertugrul et al., 2016; Mutascu, 2018). However, the influence of globalization and international trade on GHG emissions varies among countries. For instance, Dinda and Coondoo (2006) analysing developed (OECD) and developing (nonOECD) countries reported that although overarchingly $\mathrm{CO}_{2}$ emissions are stimulated by the trade openness, the influence of globalization and trade on the GHG emissions depends on the country characteristics and comparative advantage. It is obvious from the related literature that trade openness needs to be included among the potential factors to forecast GHG emissions projections.

In light of the existing literature, this paper attempts to answer the following three questions: (i) What are the economic determinants of carbon emissions that are dominant in the environmental models? (ii) Does the Environmental Kuznets Curve (EKC) exist in the G6 economies during our period of analysis? (iii) What is the most appropriate forecasting model for the levels of carbon emissions in these economies? To answer these questions and provide policy implications of the results, we conduct our investigation by using the data from G6 countries from 1978 to 2014 and some relevant empirical techniques including the Dynamic Ordinary Least Squares (DOLS), the Fully Modified OLS (FMOLS), the System-GMM estimation as well as forecasting approaches. Our key empirical findings indicate that financial development (in various forms), economic growth, trade openness and FDI have a statistically significant association with environmental degradation $\left(\mathrm{CO}_{2}\right.$ emissions) in the $\mathrm{G} 6$ economies. The economic growth, capital market expansion, and trade openness are found to be major drivers of emissions. There was weak evidence of the Environmental Kuznets Curve. The stock market capitalisation and FDI inflows have a weak but negative impact on carbon emissions. Regarding the 
forecasting performance which has not been carried out in past studies, it is quite good for the United States, Japan and Canada which are the largest per capita emitters. To improve the forecast and for inclusiveness, we enriched the model by including the energy consumption and oil prices which led to further improvement of the forecast. Our findings have profound policy implications in terms of meeting the climate commitments.

The rest of the paper is organized as follows. Section 2 introduces the empirical framework and explains the dataset. Section 3 entails a critical discussion on the empirical findings. Section 4 concludes and gives some policy implications.

\section{Methodology}

This section describes the estimation we employ to the panel data to examine the nexus between carbon emissions and their potential determinants as well as to forecast carbon emissions. As we explain later, the different econometric techniques we use in this study allow for controlling potential problems of endogeneity, heterogeneity, and cross-section dependence in panel data analysis. Another important aspect is the importance of appropriate econometric framework in the analysis of EKC. On this aspect, Wagner (2008) raised some concerns about the non-linear transformation and use of non-stationary panels to overcome the deficiencies due to the small sample and cointegration approaches which lead to further issues in the presence of cross-sectional dependencies. However, later studies indicated that there are several ways to solve these concerns (see, Stern, 2017 for details). While it is argued that the cointegration of OLS might be biased due to the linear approach (Stern, 2010), Wagner and Hong (2016) supported that the Fully-Modified OLS outperforms OLS in standard cointegrating regressions.

The traditional econometric approach to the estimation of panel data underestimates the role of cross-sectional dependence from individual dimension perspectives, over a specific time horizon. Therefore, such a method does not account for the cross-sectional effects which might interact with time variables and hence, the estimation may not be robust for each parameter. Therefore, the first and foremost step we carry out is to check whether the cross-sectional dependence exists among individual dimensions or not. More importantly, in order to ensure our variables are stationary and to avoid spurious results, we employ a rich set of stationary tests. In case we do not find the variables to be stationary at 
level but integrated of higher-order, i.e., $I(1)$ or $I(2)$ we may then apply cointegration approaches to find the long-run association among variables. Lastly, using Fully Modified Ordinary Least Squares (FMOLS) and Dynamic Ordinary Least Squares (DOLS) we will perform the estimation. The traditional OLS approach to estimation can lead to biased and non-normal distribution of the residuals. However, there are four advantages of using the subject FMOLS and DOLS approaches: (i) correcting potential dynamic heterogeneity over the cross-sectional dimensions; (ii) estimating for within-dimension estimator and between-dimension (group-mean) estimator; (iii) if have co-integration, the vectors come to average regression coefficients and (iv) the estimated t-statistics are relatively adjusted to minimize distortions. Finally, policy implications can be drawn based on results obtained from estimation.

\subsection{Cross-sectional dependence}

We employ the test proposed by Pesaran $(2004,2007)$ to examine the presence of cross-sectional dependence by considering the following dynamics:

$$
\Delta \mathrm{Y}_{\mathrm{it}}=\pi_{\mathrm{i}} \mathrm{Y}_{\mathrm{i}, \mathrm{t}-1}+\gamma_{\mathrm{i}} \xi_{\mathrm{it}}+\sum_{\mathrm{j}=1}^{\mathrm{p}-1} \theta_{\mathrm{ij}} \mathrm{Y}_{\mathrm{i}, \mathrm{t}-\mathrm{j}}+\varepsilon_{\mathrm{it}}
$$

where $\xi_{i t}$ is a deterministic component and $\sum_{j=1}^{p-1} \theta_{i j} Y_{i, t-j}$ refers to the Augmented Dickey-Fuller test. Hence, $\varepsilon_{i t}$ is considered cross-sectional for object $i$ when they have the common factors.

$$
\varepsilon_{i t}=\theta_{i} f_{t}+u_{i t}
$$

More specifically, $\theta_{i}$ explains the different impact of individuals whereas $u_{i t}$ is a white noise with no cross-sectional (i.e., they are not autocorrelated). By embedding the Eq. (2) into Eq. (1), we obtain:

$$
\Delta Y_{i t}=\pi_{i} Y_{i, t-1}+\gamma_{i} \xi_{i t}+\sum_{j=1}^{p-1} \theta_{i j} Y_{i, t-j}+\theta_{i} f_{t}+u_{i t}
$$

The cross-section dependence test among variables within panel data (for $i$ object and time $t$ ) is conducted through using Pesaran $(2004,2007)$ testing procedure with the null hypothesis being $\mathrm{H}_{0}: \theta_{i} \neq$ 0 and the alternative hypothesis being $\mathrm{H}_{\mathrm{A}}: \theta_{i}=0$.

\subsection{Stationary test}

We also perform stationary tests to check for the potential of the spurious regression problem by using stationarity testing proposed by Im-Pesaran-Shin (2003) and Levin-Lin-Chu (2002) as well as the Pesaran panel unit root test in the existence of cross-section dependence developed by Pesaran (2003) and Pesaran (2007). Table A.1. in Appendix summarizes in more detail information. 


\subsection{FMOLS \& DOLS Estimations}

The FMOLS and DOLS approaches are useful in addressing the autocorrelation issue, especially in panel data with a long-time horizon. Their main difference relies on the correction method for autocorrelated errors. While the FMOLS involves the use of Newey-West estimator to rectify the serial correlation in the residuals $u_{i t}$, the DOLS employs the lag and lead variables to achieve the same objective. The FMOLS coefficients after modification of standardized OLS is calculated as:

$$
\widehat{\beta}_{\text {FMOLS }}=\left(\sum_{\mathrm{i}=1}^{\mathrm{N}} \hat{\mathrm{L}}_{22 \mathrm{i}}^{-1} \sum_{\mathrm{t}=1}^{\mathrm{T}}\left(\mathrm{X}_{\mathrm{it}}-\bar{X}_{\mathrm{i}}\right)^{2}\right)^{-1} \sum_{\mathrm{i}=1}^{\mathrm{N}} \hat{\mathrm{L}}_{11 \mathrm{i}}^{-1} \hat{\mathrm{L}}_{22 \mathrm{i}}^{-1}\left(\sum_{\mathrm{t}=1}^{\mathrm{T}}\left(\mathrm{X}_{\mathrm{it}}-\overline{\mathrm{X}}_{\mathrm{i}}\right) \mathrm{Y}_{\mathrm{it}}^{*}-\mathrm{T} \widehat{\delta_{1}}\right)
$$

The estimation with the dependent variable and independent variables is then specified as:

$$
\mathrm{Y}_{\mathrm{it}}^{*}=\left(\mathrm{Y}_{\mathrm{it}}-\overline{\mathrm{Y}}_{\mathrm{i}}\right)-\left(\frac{\widehat{\mathrm{L}}_{21 \mathrm{i}}}{\widehat{\mathrm{L}}_{22 \mathrm{i}}}\right) \Delta \mathrm{X}_{\mathrm{it}}+\left(\frac{\widehat{\mathrm{L}}_{21 \mathrm{i}}-\widehat{\mathrm{L}}_{22 \mathrm{i}}}{\widehat{\mathrm{L}}_{22 \mathrm{i}}}\right) \beta\left(\mathrm{X}_{\mathrm{it}}-\overline{\mathrm{X}}_{\mathrm{i}}\right)
$$

The parameter $\widehat{\delta_{1}}$ in Eq. (5) is equivalent to the following expression:

$$
\widehat{\delta}_{1} \equiv \widehat{\Gamma}_{21 \mathrm{i}}+\widehat{\Omega}_{21 \mathrm{i}}^{0}-\left(\frac{\widehat{\mathrm{L}}_{21 \mathrm{i}}}{\widehat{\mathrm{L}}_{22 \mathrm{i}}}\right)\left(\widehat{\Gamma}_{22 \mathrm{i}}+\widehat{\Omega}_{22 \mathrm{i}}^{0}\right)
$$

where $\Omega, \Gamma$, and $\mathrm{L}$ refer to symptotic covariance matrix for long-run variance, the dynamic covariance, and a lower triangular matrix with partition calculation, respectively. This approach is taken to conduct FMOLS estimation. Noticeably, the FMOLS estimations can cope with two concerns: (i) generating the intercepts for specific individual regression and (ii) correcting the serial correlation properties over individual objects in the panel.

As to the DOLS estimation approach, it is performed based on the seminal study by Kao and Chiang (2001) and can be described as in Eq. (8).

$$
Y_{i t}=\beta_{i}^{\prime} x_{i t}+\sum_{j=-q}^{q} \zeta_{i j} \Delta X_{i, t+j}+\gamma_{l i l^{\prime}} D_{l i}+\varepsilon_{i t}
$$

where the $q$ refers to the numbers of lags/leads considered in the models. The significant difference between FMOLS and DOLS is the ability to correct the unbiased estimation. The DOLS outperforms the former in terms of controlling the endogeneity (peculiar problem with cointegrated variables) by using the lead and lags variables through parameter $q$ (Westerlund, 2005). Putting it differently, the error of endogeneity which appears in the equation can be accommodated in an analogous fashion using the DOLS. To gain a deeper insight, we carry out estimations by both approaches. Moreover, Zhang et al. (2017) also confirm the advantage of the DOLS method with lower root-mean-square error than Johansen's estimator, which is found in the theoretical framework of Stock and Watson (1993). These 
beneficial effects have been documented in several major studies (see, e.g., Cavusoglu \& Dincer, 2019; Dutta et al., 2019; Dincer, 2020).

\subsection{System-GMM and panel data estimation}

We also use the system Generalized Method of Moments (GMM) following the footsteps of Arellano and Bond (1991) and Blundell and Bond (1998). The system-GMM framework is extensively used in the related literature and for details, one can refer to Green (2000) and Wooldridge (2002). To briefly introduce this approach, we consider the following specification:

$$
\mathrm{Y}_{\mathrm{it}}=\gamma_{1} \Lambda_{\mathrm{it}}+\gamma_{2} \Theta_{\mathrm{it}}+\mathrm{v}_{\mathrm{i}}+\varepsilon_{\mathrm{it}}
$$

where $\mathrm{i}=1, \ldots, \mathrm{N}$ and $\mathrm{t}=1, \ldots, \mathrm{T}$. $\mathrm{Y}_{\mathrm{it}}$ is the dependent variable, whereas $\Lambda$ and $\Theta$ are exogenous covariates and predetermined covariates, respectively. $v$ is unobserved group-level effect and $\varepsilon$ is error term. The system-GMM is useful in dealing with the endogeneity issue of explanatory variables. According to Ullah et al. (2018), this method could address three sources of endogeneity such as the unobserved heterogeneity, the simultaneity and the dynamic endogeneity. Noticeably, the use of instrumental variables is more pronounced as the good approach to correct the endogeneity. Some diagnostic tests such as Sargan test and Autocorrelation tests in the first and second-orders denoted by AR(1) and AR(2) are essential in the post-estimations of the system-GMM in order to control the robustness of the estimation results. We also draw on the work of Steffensmeier et al. (2014) for forecasting the value in system-GMM estimations. Our forecasted model accounts for both endogenous and exogenous variables

to forecast the dependent variable (carbon emissions). Note that one of the most vital prerequisite condition for panel analysis in our case is the strongly balanced dataset.

\subsection{Data}

Our study uses the data of G6 countries, including Canada, France, United Kingdom, Italy, Japan, and the United States over the period from 1978 to 2014. We eliminate Germany because the data was only available since the unification of Germany in 1991. Table A.2. in Appendix shows the definition of each variable in our dataset as well as a brief explanation and data sources. To measure the degree of financial development, we choose three variables as proxies which reflect not only the development of equity and debt markets but also the number of listed firms per 10,000 habitants (financial deepening). 


\section{Empirical findings and analysis}

\subsection{Statistical properties of sample variables}

Table A.3. in Appendix shows the descriptive statistics of our variables. The skewness coefficients of $\mathrm{CO}_{2}$, Trade and GDP growth are negative, whereas they are positive for the remaining variables. The excess kurtosis is greater than zero, indicating that the probability distributions of all variables have heavy tails. These findings suggest the non-normality of considered variables, which is confirmed by the Jarque-Bera test.

The cross-sectional dependence tests using the Breusch-Pagan LM (1980), Frees (1995, 2004) and Pesaran (2004) procedures unanimously suggest the rejection of the null hypothesis at the $1 \%$ significance level, thus confirming the presence of cross-sectional dependence for our panel data variables. The null hypothesis $\mathrm{H}_{0}$ implies no cross-sectional dependence (The results of crosssectional dependence and stationarity tests are concealed to reserve the space and are available from crossponding author on request). We also perform four panel unit root tests by following the Levin-Lin-Chu (2002), Im-Pesaran-Shin (2003), Pesaran (2003) and Pesaran (2007) approaches, whereby the Pesaran panel unit root test takes the presence of cross-sectional dependence into account. The evidence of stationarity at $1 \%$ level suggests that all variables are suitable for further panel dynamic analysis.

\section{2. $\mathrm{CO}_{2}$ emissions and its determinants: evidence from FMOLS and DOLS}

As mentioned earlier, the FMOLS and DOLS are used for estimating the relationships among variables, where the FMOLS allows for rectifying the serial correlation in the error term $U_{\text {it. }}$ Table 1 summarizes our estimates of FMOLS and DOLS.

Table 1. FMOLS (with trend \& without-trend) estimation

\begin{tabular}{lccc}
\hline \multicolumn{1}{c}{ Estimation method: } & \multicolumn{2}{c}{ Fully Modified OLS } & \multirow{2}{*}{ Dynamic OLS } \\
\cline { 2 - 3 } Long-run coefficient & Trend & No-trend & -0.020 \\
FDI to GDP & 0.001 & 0.001 & {$[-2.22]$} \\
Trade openness & {$[-2.17]$} & {$[-2.06]$} & 0.010 \\
& $0.050^{* * * *}$ & $0.060^{* * * *}$ & {$[-3.31]$} \\
GDPgrowth & {$[5.88]$} & {$[5.41]$} & $1.420^{* * * *}$ \\
& $0.850^{* * * *}$ & $0.840^{* * * *}$ & {$[7.04]$} \\
Stock_Market_Value & {$[18.56]$} & {$[17.02]$} & 0.010 \\
& -0.001 & -0.001 & {$[0.36]$} \\
No_listed_firms & {$[-1.45]$} & {$[-1.28]$} & 0.050 \\
Loans & $0.020^{* * * *}$ & $0.020^{* * * *}$ & {$[0.83]$} \\
\hline
\end{tabular}


$\frac{[-2.25]}{\text { Notes: }{ }^{* * *},{ }^{* *} \text { and }{ }^{*} \text { indicates the statistical significance at } 1 \%, 5 \% \text {, and } 10 \% \text {, levels, whereas } \text { t-statistics are }}$ reported in the brackets.

As seen from the table above, we can see that our results are consistent in both cases with the trend and without a trend. There are three factors, which positively contribute to the $\mathrm{CO}_{2}$ emission in G6 countries these are the trade, GDP growth and number of listed companies in the stock exchange. The results for the trade, GDP growth and number of listed firms are also significant at $1 \%$ level. To be more precise, at a $1 \%$ significance level, the $\mathrm{CO}_{2}$ emission will increase by $0.05 \%$ and $0.06 \%$ by trend and no-trend model, respectively when the trade as a percentage of GDP increases by $1 \%$. Meanwhile, the one per cent increase of the GDP growth will lead to $0.85 \%$ and $0.84 \%$ by trend and no-trend models, respectively, at $1 \%$ significance level. With regards to the financial development, the financial deepening as measured by listed firms leads to more percentage of $\mathrm{CO}_{2}$ emission. Therefore, an increase in listed firms results in environmental deterioration. However, there is weak evidence suggesting that loan from non-residence and stock market capitalization have a negative influence on the $\mathrm{CO}_{2}$ emission in G6 countries. This implies that neither the increase in the capitalisation of the stock market of existing firms nor the loans from non-residents deteriorate the environment. Regarding the commonly focused determinants such as GDP growth, FDI, and trade openness, our findings also confirm the existing evidence (Nasir et al., 2019; Nguyen et al., 2020). After FMOLS, we will employ the DOLS for further investigation of the influence of these variables on $\mathrm{CO}_{2}$ emission. The benefit of using DOLS is that it employs the lead and lagged variables to correct the serial correlation in the residual term $\mathrm{U}_{\mathrm{it}}$.

In the DOLS estimation, only GDP growth is found to be significant at $1 \%$ level, implying that the economic growth in the G6 countries adversely affects the environment. To be more precise, if the GDP growth increases by $1 \%$, the $\mathrm{CO}_{2}$ emissions will also increase by $1.42 \%$ at $1 \%$ level of statistical significance. overarchingly, in terms of the direction of causality, our results in DOLS are similar to the FMOLS estimation. In nutshell, we infer that the effect of GDP growth on the environment in G6 countries is very strong. However, we conducted a further investigation with the presence of a quadratic term of GDP (i.e., GDP squared) in order to test the long-run link between economic growth and ecological degradation. The empirical findings are presented in Table 2. 
Table 2. Estimation of Environmental Kuznets Curve: FMOLS \& DOLS approaches

\begin{tabular}{ccc}
\hline Estimation method: & \multicolumn{2}{c}{ Estimation } \\
\cline { 2 - 3 } Long-run coefficients & Fully Modified OLS & Dynamic OLS (DOLS) \\
\hline \multirow{2}{*}{ FDI to GDP } & 0.001 & -0.030 \\
& {$[-1.81]$} & {$[-3.58]$} \\
GDPgrowth squared & 0.920 & -32.180 \\
& {$[-0.25]$} & {$[-6.84]$} \\
Trade Openess & $0.050^{* * *}$ & -0.120 \\
& {$[4.74]$} & {$[-2.00]$} \\
GDPgrowth & $0.770^{* * *}$ & $2.130^{* * *}$ \\
& {$[15.28]$} & {$[13.03]$} \\
Stock_Market_Value & -0.001 & $0.060^{* * *}$ \\
& {$[-1.05]$} & {$[1.92]$} \\
No_listed_firms & $0.010^{* * *}$ & $0.140^{* * *}$ \\
& {$[3.84]$} & {$[3.91]$} \\
Loans & -0.020 & -0.040 \\
& {$[-1.64]$} & {$[-4.79]$} \\
Notes: ${ }^{* * * *},{ }^{* *}$ and ${ }^{*}$ indicates the statistical significance at 1\%, 5\%, and 10\%, levels, whereas t-statistics are
\end{tabular}

There are some differences between FMOLS and DOLS in terms signs of coefficients, including the FDI, GDP squared, Trade and Stock market capitalization. One of our explanation is about the existence of $\mathrm{GDP}^{2}$, which might cause endogenous errors. Therefore, we considered employing the system-GMM on panel data. Focusing on our results from FMOLS and DOLS for Environmental Kuznets Curve, it showed that the GDP growth and increase in the number of listed companies deteriorate the G6 environment at $1 \%$ level of statistical significance. When it comes to FMOLS regression, trade plays an active role to increase the $\mathrm{CO}_{2}$ emission in $\mathrm{G} 6$ countries. More importantly, there is no evidence to confirm the Environmental Kuznets Curve in FMOLS because the sign of GDP squared coefficient is positive. As regards DOLS, the negative coefficient of GDP (-32.18) demonstrates that the Environmental Kuznets Curve exists in the G6 countries, however, it remains insignificant. The DOLS estimation also suggests that the stock market capitalization positively influences the $\mathrm{CO}_{2}$ emission at $1 \%$ significance level. To sum up, we conclude that the Environmental Kuznets Curve is not clear whereas the rest of the results are quite similar and consistent with our earlier findings, although prior studies confirm the existence of EKC (Nasir et al., 2019; Nguyen et al., 2020). In the next part, we perform the panel data estimation for robustness.

\section{3. $\mathrm{CO}_{2}$ emissions and its determinants: evidence from panel estimations}

Employing a set of quantitative techniques including Pooled-OLS, Fixed Effect Model (FEM), Random Effect Model (REM) and system-GMM, Table 3 shows that except loans by non-residents, all the 
variables have a significant impact at the $1 \%$ level. Among these variables, FDI and stock market capitalization decrease the $\mathrm{CO}_{2}$ emission as their coefficients are negative. Meanwhile, the remaining variables have positive coefficients implying that they foster the $\mathrm{CO}_{2}$ emission. Our estimations are quite robust as the Sargan-Hansen test of over-identifying restrictions, showed that the null hypothesis was not rejected. Furthermore, $\mathrm{AR}(1)$ and $\mathrm{AR}(2)$ tests of first- and second-order serial correlation in residuals fail to reject the null hypothesis that instrumental variables are uncorrelated with the residuals. Furthermore, we drew on the studies by Ullah et al. $(2018,2020)$ to address the endogeneity issue. The obtained results thus do not suffer from statistical biases.

Table 3. Panel estimations

\begin{tabular}{ccccc}
\hline \multirow{2}{*}{ Variables } & \multicolumn{4}{c}{ Estimation method } \\
\cline { 2 - 5 } & Pooled-OLS & Fixed-Effect & Random-Effect & System-GMM \\
\hline \multirow{2}{*}{ FDI to GDP $\left(\times 10^{-4}\right)$} & -0.582 & -0.745 & -0.582 & $-0.642^{* * *}$ \\
& {$[-1.05]$} & {$[-1.36]$} & {$[-1.05]$} & {$[-13.26]$} \\
Trade Openess & $0.083^{* *}$ & $0.077^{* *}$ & $0.083^{* * * *}$ & $0.089^{* * * *}$ \\
& {$[2.61]$} & {$[2.46]$} & {$[2.61]$} & {$[3.84]$} \\
GDPgrowth & $0.836^{* * *}$ & $0.889^{* * *}$ & $0.836^{* * *}$ & $0.752^{* * *}$ \\
& {$[7.66]$} & {$[8.07]$} & {$[7.66]$} & {$[12.55]$} \\
Stock_Market_Value & -0.004 & -0.007 & -0.004 & $-0.006^{* * *}$ \\
& {$[-0.70]$} & {$[-1.09]$} & {$[-0.70]$} & {$[-3.47]$} \\
No_listed_firms & $0.023^{* * *}$ & $0.023^{* * *}$ & $0.023^{* * * *}$ & $0.030^{* * * *}$ \\
& {$[2.72]$} & {$[2.77]$} & {$[2.72]$} & {$[6.93]$} \\
Loans & -0.009 & -0.010 & -0.009 & -0.006 \\
& {$[-0.71]$} & {$[-0.73]$} & {$[-0.71]$} & {$[-0.33]$} \\
Constant & $-0.024^{* * *}$ & $-0.025^{* * *}$ & $-0.024^{* * * *}$ & $-0.023^{* * *}$ \\
AR(1) & {$[-7.41]$} & {$[-7.73]$} & {$[-7.41]$} & {$[-4.84]$} \\
AR(2) & & & & 0.066 \\
Sargan Test & & & & 0.129 \\
\hline
\end{tabular}

Notes: ${ }^{* * * *},{ }^{* *}$ and ${ }^{*}$ indicates the statistical significance at $1 \%, 5 \%$, and $10 \%$ levels, whereas $t$-statistics are reported in the brackets.

In Table 4, we re-examine the Environmental Kuznets Curve by panel data estimation with the same techniques. Our results with the presence of GDP squared are not different from the previous estimations (Table 2). However, the quadratic term of GDP is also insignificant although the sign of the coefficient is negative. FDI and stock market capitalization value are found to be important elements to decrease the $\mathrm{CO}_{2}$ emission in $\mathrm{G} 6$ countries at $1 \%$ significance level. In contrast, the existence of trade, growth of GDP and number of listed firms harmfully influence $\mathrm{CO}_{2}$ emission at the $1 \%$ level.

Table 4. Environmental Kuznets Curve for panel estimation

\begin{tabular}{ccccc}
\hline \multirow{2}{*}{ Variables } & \multicolumn{4}{c}{ Estimation method } \\
\cline { 2 - 5 } & Pooled-OLS & Fixed-Effect & Random-Effect & System-GMM \\
\hline \multirow{2}{*}{ FDI $\left(\times 10^{-4}\right)$} & -0.575 & -0.725 & -0.575 & $-0.571^{* * *}$ \\
& {$[-1.03]$} & {$[-1.32]$} & {$[-1.03]$} & {$[-7.82]$} \\
Trade & 0.080 & $0.070^{* * *}$ & $0.080^{* *}$ & $0.069^{* * *}$ \\
& {$[2.41]$} & {$[2.15]$} & {$[2.41]$} & {$[2.86]$}
\end{tabular}




\begin{tabular}{|c|c|c|c|c|}
\hline GDPgrowth $^{2}$ & -0.760 & -1.861 & -0.760 & -1.435 \\
\hline & $0.859^{* * * *}$ & $0.944^{* * *}$ & $0.859^{* * * *}$ & $0.857^{* * * *}$ \\
\hline GDPgrowth & {$[5.96]$} & {$[6.61]$} & {$[5.96]$} & {$[5.59]$} \\
\hline \multirow{2}{*}{ Stock_Market_Value } & -0.005 & -0.007 & -0.005 & $-0.006^{* * * *}$ \\
\hline & {$[-0.71]$} & {$[-1.11]$} & {$[-0.71]$} & {$[-4.48]$} \\
\hline \multirow{2}{*}{ No_listed_firms } & 0.023 & 0.023 & 0.023 & $0.025^{* * *}$ \\
\hline & [2.69] & [2.70] & [2.69] & [4.31] \\
\hline \multirow{2}{*}{ Loans } & -0.009 & -0.008 & -0.009 & -0.002 \\
\hline & {$[-0.67]$} & {$[-0.61]$} & {$[-0.67]$} & {$[-0.12]$} \\
\hline \multirow{2}{*}{ Constant } & $-0.024^{* * * *}$ & $-0.024^{* * *}$ & $-0.024^{* * *}$ & $-0.025^{* * *}$ \\
\hline & {$[-7.21]$} & {$[-7.44]$} & {$[-7.21]$} & {$[-4.98]$} \\
\hline $\mathrm{AR}(1)$ & & & & 0.059 \\
\hline $\mathrm{AR}(2)$ & & & & 0.104 \\
\hline Sargan test & & & & 0.347 \\
\hline
\end{tabular}

Notes: ${ }^{* * * *},{ }^{* *}$ and ${ }^{*}$ indicates the statistical significance at $1 \%, 5 \%$, and $10 \%$ levels, whereas $t$-statistics are reported in the brackets.

\subsection{Forecasting and evaluation}

First, we perform the regression over the period from 1978 to 2004, then draw projections of $\mathrm{CO}_{2}$ emission based on our estimated models, and finally make a comparison of how our model fits to forecast with the actual data. The graphs for each country in Figure 1 demonstrate our forecasting results.

As our results suggest, the red lines are our forecasted value of $\mathrm{CO}_{2}$ emissions while the blue lines are the actual $\mathrm{CO}_{2}$ emissions. In most of the cases, our forecasted values in $\mathrm{G} 6$ countries share the same patterns with the actual ones. Noticeably, our forecasted model is not well fitted for Great Britain after 2010 whereas the predicted values are in line for Canada and Japan. Therefore, our model performs well for most of the countries, but it is likely to be noise fluctuation for Great Britain. While three countries, namely France, Italy, and Great Britain, were forecasted to have a significant increase in the amount of carbon emissions (for example, the average discrepancies between the forecasted value and actual value of these countries are $0.019,0.024$, and 0.023 , correspondingly), the actual emissions seem to be lower than expected. In contrast, the United State and Canada seem to experience a higher level of carbon emissions than forecasted. 


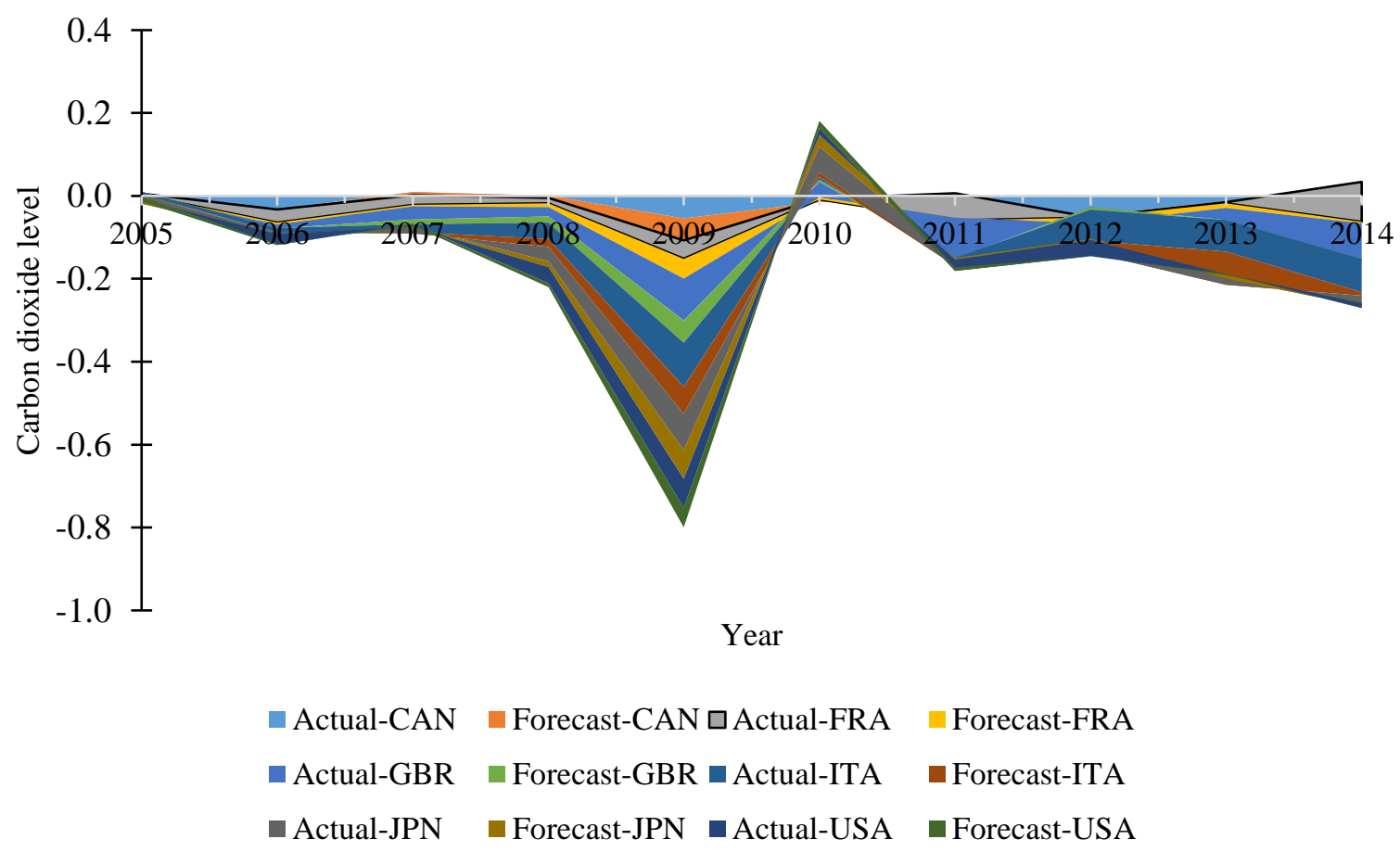

CAN, FRA, GBR, ITA, JPN, and USA denote Canada, France, the Great Britain, Italy, Japan, and the United States.

Figure 1. Forecasted and actual values of $\mathrm{CO}_{2}$ emission (\%) in G6 countries

\subsection{Forecasting model extension}

To further improve our forecasting models and to take a more inclusive and conclusive approach, we drew on the recent studies which emphasise the role of energy consumption and oil prices in $\mathrm{CO}_{2}$ emissions (Muhammad, 2019; Pao and Chen, 2019; Matos et al. 2019; Lin and Raza, 2019; Wang et al., 2019; Dutta et al., 2018). Concomitantly, we also employ the system-GMM to forecast the carbon dioxide by including energy consumption and oil prices (West Texas Intermediate). Data are collected from the World Development Indicators database and the U.S. Energy Information Administration. This will also be helpful in making a comparison between the models. Table 5 presents our initial results with the system-GMM approach over the period 1978-2004.

Table 5. Panel estimation with energy consumption and oil prices

\begin{tabular}{ccccc}
\hline \multirow{2}{*}{ Variables } & \multicolumn{4}{c}{ Estimation method } \\
\cline { 2 - 4 } & Pooled-OLS & Fixed-Effect & Random-Effect & System-GMM \\
\hline \multirow{2}{*}{ FDI to GDP } & -0.0000317 & -0.0000358 & -0.0000317 & -0.0002046 \\
& {$[-0.89]$} & {$[-1.04]$} & {$[-0.89]$} & {$[-0.91]$} \\
Trade Openness & $0.037^{*}$ & $0.036^{*}$ & $0.037^{*}$ & $0.031^{* * *}$ \\
& {$[1.73]$} & {$[1.76]$} & {$[1.73]$} & {$[4.19]$} \\
GDPgrowth & $0.172^{* *}$ & 0.129 & $0.172^{* *}$ & $0.235^{* *}$ \\
& {$[2.09]$} & {$[1.56]$} & {$[2.09]$} & {$[2.39]$} \\
Stock_Market_Value & -0.003 & -0.002 & -0.003 & -0.006 \\
& {$[-0.87]$} & {$[-0.63]$} & {$[-0.87]$} & {$[-1.10]$}
\end{tabular}




$\begin{array}{ccccc}\text { No_listed_firms } & 0.005 & 0.005 & 0.005 & 0.000 \\ & {[0.91]} & {[1.03]} & {[0.91]} & {[0.15]} \\ \text { Loans } & -0.008 & -0.008 & -0.008 & -0.002 \\ & {[-0.95]} & {[-0.94]} & {[-0.95]} & {[-0.14]} \\ \text { Energy Consumption } & 0.975^{* * *} & 1.001^{* * * *} & 0.975^{* * *} & 1.088^{* * *} \\ & {[16.86]} & {[17.43]} & {[16.86]} & {[9.81]} \\ \text { Oil Prices } & 0.000 & 0.000 & 0.000 & 0.000^{*} \\ & {[0.85]} & {[0.97]} & {[0.85]} & {[1.73]} \\ \text { Constant } & -0.011^{* * * *} & -0.011^{* * *} & -0.011^{* * *} & -0.021^{* * * *} \\ \text { AR(1) } & {[-3.16]} & {[-3.12]} & {[-3.16]} & {[-6.19]} \\ \text { AR(2) } & & & & 0.054 \\ \text { Sargan test } & & & & 0.859 \\ \text {, } & & & 0.235\end{array}$

Notes: ${ }^{* * * *},{ }^{* *}$ and ${ }^{*}$ indicates the statistical significance at $1 \%, 5 \%$, and $10 \%$ levels, whereas $t$-statistics are reported in the brackets.

Based on the results from Table 9, it can be intuitively argued that energy consumption, as well as oil prices, play a critical role in explaining the $\mathrm{CO}_{2}$ emissions in $\mathrm{G} 6$ countries. Irrespective of the choice of the model, energy consumption impact is statistically significant at the $1 \%$ level in all our models whereas oil prices also became a good indicator after correcting the endogeneity. It is worth noting that the signs of all our coefficients are consistent. Therefore, we proceed with the forecasting $\mathrm{CO}_{2}$ emissions and comparison with the real values as represented in Figure 2.

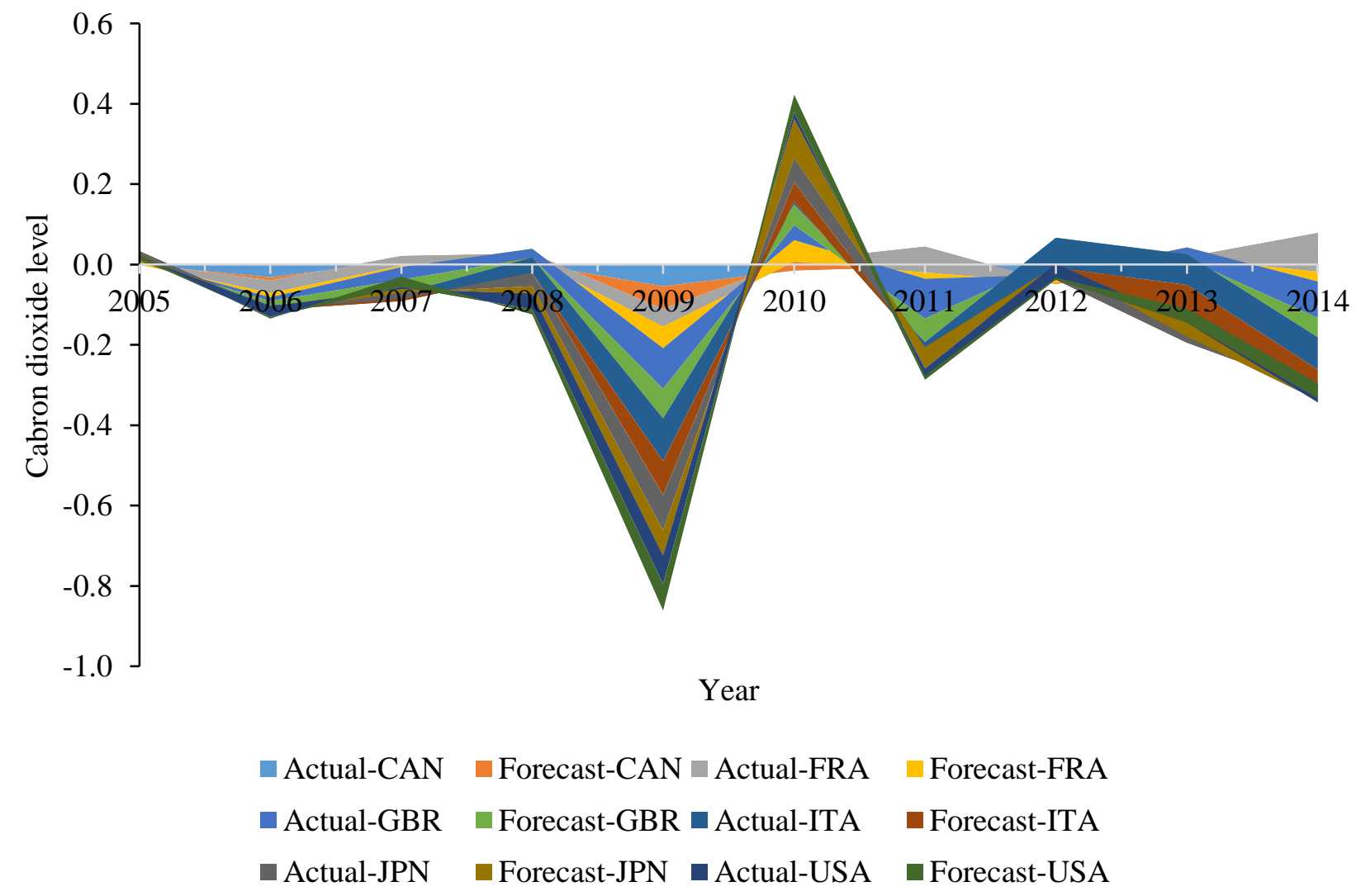

CAN, FRA, GBR, ITA, JPN, and USA denote Canada, France, the Great Britain, Italy, Japan, and the United States.

Figure 2. Forecasting $\mathrm{CO}_{2}$ emissions (\%) with energy consumption and oil prices 
The latter forecast performance is prima facie better than the previous one. Forecast values are closely in line with the actual $\mathrm{CO}_{2}$ emissions by $\mathrm{G} 6$ countries. Interestingly, our predicted models raise further research matter for the case of Italy and Japan. Based on forecasting values, after 2012, the $\mathrm{CO}_{2}$ emissions in Italy and Japan have been slightly higher than forecast. However, the actual amount of carbon dioxide emissions and forecast converged and in fact, the former slightly decreased. This may refer to the good policy implemented to control against the increasing $\mathrm{CO}_{2}$ emission without impeding on economic growth and other determinants of emissions. A matter might of interest for further research. In a nutshell, our models having the presence of energy consumption and oil prices factors, outperform in terms of forecasting the environmental degradation associated with $\mathrm{CO}_{2}$ emission.

\section{Conclusion}

The empirical findings lead us to conclude on strong evidence of an association among economic growth, financial development, foreign direct investment, trade openness and $\mathrm{CO}_{2}$ emissions. The economic growth in the underlying G6 economies is the most crucial factor and contributor to $\mathrm{CO}_{2}$ emissions. This finding would imply that solely focusing on the GDP growth will have drastic ecological consequences and, in order to honour the Paris Agreement (COP21), the economies in question would need to take a more sustainable perspective of growth. They should not focus only on the GDP figure, but also on the quality of growth which encompasses low-emission and climate-resilient economic sectors. The lack of a strong evidence regarding the Environmental Kuznets Curve enforces the needs of a more inclusive and sustainable approach to economic growth. Similar to the findings for the link between growth and $\mathrm{CO}_{2}$, trade openness affects significanty and positively the carbon emissions, which also calls for more attention to sustainability aspects of international trade in addition to GDP quality.

In terms of financial development, the results show that the expansion of capital markets in terms of listed firms leads to increases in carbon emissions, whereas the rise in market capitalisation has a weak but negative impact on carbon emissions. On the other hand, the loans or credit creation have a negative but insignificant impact on carbon emissions. These results suggest that governments can fight environmental degradation by favouring the development of bank loans and the efficiency of capital markets because they are critical to firms' ability to access to finance and require more sustainable engagement about the way conduct their business activities. For instance, Goss and Roberts (2011) 
investigate the link between bank loans and corporate social responsibility (CSR) for a sample of 3996 loans to US firms and typically show that loans are less expensive for more responsible firms. With the increased societal pressure and climate emergency, corporate stakeholders are also more willing to lend money to firms with environmental, social, and governance (ESG) concerns, which push corporate leaders and investment fund managers to care about sustainability. This movement has been documented for corporate leaders and fund managers as shown in Eccles and Klimenko (2019) whose conducted interviews with 70 senior executives at 43 global institutional investing firms such as BlackRock, Vanguard, State Street, the California Public Employees' Retirement System, the California State Teachers' Retirement System, and the government pension funds of Japan, Sweden, and the Netherlands.

Regarding the FDI, it has a negative impact on $\mathrm{CO}_{2}$ emissions, which is intuitive as the G6 economies are well developed and do not seem to be pollution heavens for unsustainable investments. This result would give incentives to G6 governments to strengthen the shift to low carbon investments, and particularly investments for clean energy generation (e.g., opening plants with renewable-energyorientation) in order to satisfy the energy need. The United States is a good example of how the huge FDI inflows (US\$ 246 billion in 2019 according to UNCTAD's World Investment Report 2020) could be directed to develop solar energy that experienced the largest growth between 2008 ( 2 billion kilowatthours) and 2018 (more than 93 billion kilowatt-hours), but this energy source still represents only 1\% of the national total energy production.

The forecasting performance of the model suggests that in most of the G6 countries, particularly the major players (e.g, United States and Japan) and high per capita emitter (e.g., Canada), the emissions were in line with the predictions by the model. For Italy and France, the results of the model were also good in terms of forecasting for a number of years. The forecast for the United Kingdom seemed to be weak, though performed well in the earlier years. After the modification and making it more inclusive by including the energy consumption and oil prices, the forecasting performance for all the countries significantly increase. This implies that, in addition to the other economic and financial factors, energy consumption and oil prices are crucial factors to account for carbon emissions. In a policy setting, it will require active market and price intervention to deal with the ecological consequences of energy use and oil price slumps. 
Overall, our results suggest that the economic growth, trade, financial development (with its various facets) and FDI have important ecological implications and, therefore, provides a good insight into the future dynamics of carbon emissions. The sample countries should thus take into account the legal promulgation of sustainable development, attract the green FDI, and concentrate on green financial development without low carbon engagement. Moreover, further agreement and concrete steps are required to balance the costs of withdrawal of the United Sates from the COP21. Finally, the level of energy consumption and oil prices are also important to determine future emissions.

While this study focused on the G6 economies due to their importance in terms of economic size and carbon emissions, climate change is not an issue faced by a single or a group of countries. This is a global issue which requires a global effort and a global cooperation. The subject study can thus be extended, for instance, by considering other important emerging and developing economies such as BRICS, G20 countries, and ASEAN. Due to the unavailability of some data, our sample ends in 2014. Future research may extend not only the dataset, but also the analysis by including other factors such as decomposition of energy consumption with renewable energy, energy prices, other economic and social factors, waste pollution, and other forms of GHG emissions, in order to capture the dynamic changes in carbon emissions. Furthermore, future research could also focus on the other empirical approaches such as machine learning and employing higher frequency dataset to forecast the dynamic levels of carbon emissions.

\section{References}

Abdouli, M., Hammami, S., 2017. Investigating the causality links between environmental quality, foreign direct investment and economic growth in MENA countries. Int. Bus. Rev., 26, 264-278. 
Al-Mulali, U., Ozturk, I., 2016. The investigation of environmental Kuznets curve hypothesis in the advanced economies: the role of energy prices. Renew. and Sustain. Energy Rev. 54, 1622-1631.

Al-Mulali, U., Tang, C.F., 2013. Investigating the validity of pollution haven hypothesis in the gulf cooperation council (GCC) countries. Energy Policy 60, 813-819.

Antweiler, W. Copeland, B.R. Taylor, M. S. 2001. Is free trade good for the environment? American Econ. Rev. 91, 877-908

Apergis, N., 2016. Environmental Kuznets curves: new evidence on both panel and country-level CO2 emissions. Energy Econ. 54, 263-271.

Baek, J. 2015. Environmental Kuznets curve for CO2 emissions: The case of Arctic countries. Energy Econ. 50, 13-17.

Campiglio, E., 2016. Beyond carbon pricing: The role of banking and monetary policy in financing the transition to a low-carbon economy. Ecol. Econ. 121, 220-230,

Caviglia-Harris, J.L., Chambers, D. Kahn, J.R., 2009. Taking the "U" out of Kuznets: A comprehensive analysis of the EKC and environmental degradation, Ecol. Econ., 68, 1149-1159.

Cavusoglu, T., \& Dincer, O. 2019. Schooling and income inequality in the long-run. J. Econ. and Finance, 43(3), 594-606.

Chang, S.C., 2015. Effects of financial developments and income on energy consumption. Int. Rev. Econ. and Finance 35, 28-44.

Charfeddine, L., Khediri, K.B., 2016. Financial development and environmental quality in UAE: cointegration with structural breaks. Renew. \& Sustain. Energy Rev., 1322-1335.

Chiu, Y-B., 2017. Carbon dioxide, income and energy: evidence from a non-linear model. Energy Econ. 61, 27988.

Çoban, S., Topcu, M., 2013. The nexus between financial development and energy consumption in the EU: a dynamic panel data analysis. Energy Econ. 39, 81-88.

Cole, M.A., Fredriksson, P.G., 2009. Institutionalized pollution havens, Ecol. Econ. 68(4), 1239-1256.

David I. Stern, Between estimates of the emissions-income elasticity, Ecol. Econ., Volume 69, Issue 11, 2010, Pages 2173-2182

Dinda, S., Coondoo, D., 2006. Income and emission: a panel data based cointegration analysis. Ecol. Econ. 57(2), 167-181.

Dincer, O. (2020). If you're corrupt, you'd better be free. J. Econ. Stud. Available online.

Dutta, A., Bouri, E., Noor, M.H., 2018. Return and volatility linkages between CO2 emission and clean energy stock prices. Energy. 164, 803-810.

Dutta, U. P., Gupta, H., \& Sengupta, P. P. 2019. ICT and health outcome nexus in 30 selected Asian countries: Fresh evidence from panel data analysis. Technol. in Soc., 59, 101184.

Eccles, R. G., Klimenko, S., 2019. The investor revolution. Harvard Bus. Rev., 97(3), 106-116.

Ertugrul, H.M., Cetin, M., Seker, F., Dogan, E., 2016. The impact of trade openness on global carbon dioxide emissions: Evidence from the top ten emitters among developing countries. Ecol. Indict. 67, 543-555.

Goss, A., Roberts, G. S., 2011. The impact of corporate social responsibility on the cost of bank loans. J. Bank. \& Finance, 35(7), 1794-1810.

Grossman, G.M., Krueger, A.B., 1991. Environmental impacts of a North American Free Trade Agreement. National Bureau of Economic Research Working Paper 3914, NBER. Cambridge MA. doi:10.3386/w3914.

Green, W.H., 2000. Econ. Anal., New Jersey, Prentice-Hall Inc.

Im, K.S., Pesaran, M.H., Shin, Y., 2003. Testing for unit roots in heterogeneous panels. J. Econom. 115, 53-74.

Javid, M., Sharif, F., 2016. Environmental Kuznets curve and financial development in Pakistan. Renew. and Sustain. Energy Rev. 54, 406-414.

Jiang, L., Zhou, H.-F., Bai, L., Zhou, P., 2017. Does foreign direct investment drive environmental degradation in China? An empirical study based on air quality index from a spatial perspective, J. Clean. Prod. 1-9 
Kao, C., Chiang, M.H., 2001. On the estimation and inference of a cointegrated regression in panel data. Advances in Econometrics 15, 179-222.

Kivyiro, P., Arminen, H., 2014. Carbon dioxide emissions, energy consumption, economic growth, and foreign direct investment: causality analysis for Sub-Saharan Africa. Energy 74, 595-606.

Lee, J. W., 2013. The contribution of foreign direct investment to clean energy use, carbon emissions and economic growth. Energy Policy 55, 483-489.

Levin, A., Lin, C.-F., Chu, C.-S. J., 2002. Unit root tests in panel data: Asymptotic and finite-sample properties. J. Econom. 108, 1-24.

Leimbach, M., Roming, N., Schultes, A., Schwerhoff, G., 2018. Long-Term Development Perspectives of SubSaharan Africa under Climate Policies. Ecol. Econ. 144, 148-159.

Lin, B., Raza, M.Y., 2019. Analysis of energy related CO2 emissions in Pakistan. J. Clean. Prod. 219, 981-993.

Liu, Y., Hao, Y., Gao, Y., 2017. The environmental consequences of domestic and foreign investment: evidence from China. Energy Policy 108, 271-280.

McAusland, C., 2008. Trade, politics, and the environment: Tailpipe vs. Smokestack. J. Environ. Econ. and Manag. $55,52-71$

Morgan, J., 2016. Paris COP 21: Power that Speaks the Truth? Glob., 13, 943-951.

Matos, C., Bentes, I., Pereira, S., Faria, D., Briga-Sá, A. 2019. Energy consumption, CO2 emissions and costs related to baths water consumption depending on the temperature and the use of flow reducing valves. Science of the Total Environment 646, 280-289.

Muhammad, B., 2019. Energy consumption, CO2 emissions and economic growth in developed, emerging and Middle East and North Africa countries. Energy 179(7), 232-245.

Mutascu, M., 2018. A time-frequency analysis of trade openness and CO2 emissions in France. Energy Policy 115 , 443-455.

Naughton, H.T., 2014. To shut down or to shift: Multinationals and environmental regulation. Ecol. Econ. 102, 113-117,

Nasir, M. A., Ahmed, F., Ahmed, M., Wu, J., 2015. Financial and economic stability as 'two sides of a coin': Noncrisis regime evidence from the UK based on VECM. Journal of Financial Economic Policy 7, 327-353.

Nasir, M. A. Huynh, T. L.D. Tram, H. T. X. (2019), Role of financial development, economic growth \& foreign direct investment in driving climate change: A case of emerging ASEAN. J. Environ. Manag., 242, 131-141.

Newey, W.K., West, K.D., 1994. Automatic lag selection in covariance matrix estimation. Review of Economic Studies 61, 631-653.

Nguyen, T. T., Pham, T. A. T., \& Tram, H. T. X. (2020). Role of information and communication technologies and innovation in driving carbon emissions and economic growth in selected G-20 countries. J. Environ. Manag., $261,110162$.

Omri, A., Daly, S., Rault, C., Chaibi, A., 2015. Financial development, environmental quality, trade and economic growth: what causes what in MENA countries. Energy Econ. 48, 242-252

Onafowora, O.A., Owoye, O., 2014. Bounds testing approach to analysis of the environment Kuznets curve hypothesis. Energy Econ. 44, 47-62.

Özokcu, S., Özdemir, Ö., 2017. Economic growth, energy, and environmental Kuznets curve. Renew. \& Sustain. Energy Rev.. 72, 639-647

Ozturk, I., Acaravci, A., 2013. The long-run and causal analysis of energy, growth, openness and financial development on carbon emissions in Turkey. Energy Econ. 36, 262-267

Pao, H.T., Chen, C.C., 2019. Decoupling strategies: CO2 emissions, energy resources, and economic growth in the Group of Twenty. J. Clean. Prod. 206, 907-919.

Pao, H.T., Tsai, C.-M., 2011. Multivariate Granger causality between CO2 emissions, energy consumption, FDI (foreign direct investment) and GDP (gross domestic product): evidence from a panel of BRIC (Brazil, Russian Federation, India, and China) countries. Energy 36, 685-693.

Paramati, S.R., Ummalla, M., Apergis, N., 2016. The effect of foreign direct investment and stock market growth on clean energy use across a panel of emerging market economies. Energy Econ., 56, 29-41. 
Pesaran, M.H., 2003. A Simple Panel Unit Root Test in the Presence of Cross Section Dependence. Cambridge Working Papers in Economics 0346, Faculty of Economics (DAE), University of Cambridge.

Pesaran, M.H., 2004. General diagnostic tests for cross section dependence in panels. University of Cambridge, Faculty of Economics, Cambridge Working Papers in Economics No. 0435.

Pham, N.M. Huynh, T.L.D Nasir, M.A. (2020), Environmental consequences of population, affluence and technological progress for European countries: A Malthusian view, J. Environ. Manag., 260, 110143.

Ren, S., Yuan, B., Ma, X., Chen, X., 2014. International trade, FDI (Foreign Direct Investment) and embodied CO2 emissions: a case study of Chinas industrial sectors. China Economic Review. 28, 123-134.

Rezza, A.A., 2013. FDI and pollution havens: Evidence from the Norwegian manufacturing sector. Ecol. Econ. 90, 140-149.

Salahuddin, M., Alam, K., Ozturk, I., Sohag, K., 2018. The effects of electricity consumption, economic growth, financial development and foreign direct investment on CO2 emissions in Kuwait. Renew. and Sustain. Energy Rev. 81, 2002-2010.

Shahbaz, M. Mallick, H. Mahalik, M. K. Loganathan, N., 2015. Does globalization impede environmental quality in India? Ecol. Indict. 52, 379-393

Shahbaz, M., Shahzad, S.J.H., Ahmad, N., Alam, S., 2016. Financial development and environmental quality: the way forward. Energy Policy 98, 353-364.

Shahbaz, M., Nasir, M.A., Roubaud, D., 2018. Environmental degradation in France: The effects of FDI, financial development, and energy innovations. Energy Econ., 74, 843-857.

Shahbaz, M. Sinha, A. (2019), "Environmental Kuznets curve for CO2 emissions: a literature survey", J. Econ. Stud., 46. 106-168

Shahbaz, M. Kablan, S. Hammoudeh, S. Nasir M. A. Kontoleon, A. (2020), Environmental implications of increased US oil production and liberal growth agenda in post -Paris Agreement era, J. Environ. Manag., 271, 110785 .

Stern, D. I. 2017. The environmental Kuznets curve after 25 years. J. Bioecon., 19(1), 7-28.

Stock, J. H., \& Watson, M. W. 1993. A simple estimator of cointegrating vectors in higher order integrated systems. Econometrica: J. the Econ. Soc., 783-820.

Tamazian, A., Chousa, J.P., Vadlamannati, K.C., 2009. Does higher economic and financial development lead to environmental degradation: evidence from BRIC countries. Energy Policy 37, 246-253.

Tamazian, A., Rao, B.B., 2010. Do economic, financial and institutional developments matter for environmental degradation? Evidence from transitional economies. Energy Econ. 32, 137-145

Tang, C.F., Tan, B.W., 2015. The impact of energy consumption, income and foreign direct investment on carbon dioxide emissions in Vietnam. Energy 79, 447-454

Tol, R. 2015. The road from Paris: International climate policy after the Paris agreement of 2015, Vox, CEPR Policy Portal, available at https://voxeu.org/article/road-cop21

Yuan, F., Gallagher, K.P., 2018. Greening development lending in the Americas: Trends and determinants. Ecol. Econ. 154, 189-200.

Wagner. M. 2008. The carbon Kuznets curve: A cloudy picture emitted by bad econometrics? Resour. and Energy Econ., 30, 3, 388-408.

Wagner, M., \& Hong, S. H. 2016. Cointegrating polynomial regressions: fully modified OLS estimation and inference. Econom., 32(5), 1289-1315.

Wang, X., Bai, M., Xie, C., 2019. Investigating CO2 mitigation potentials and the impact of oil price distortion in China's transport sector. Energy Policy 130, 320-327.

Westerlund, J. 2005. Data dependent endogeneity correction in cointegrated panels. Oxford Bulletin of Econ. and Stat., 67(5), 691-705.

World Bank 2017. CO2 emissions available at [http://data.worldbank.org/indicator/EN.ATM.CO2E.PC]

Wooldridge, J.M. 2002. Econ. Anal. of Cross Section and Panel Data. Cambridge, Massachusetts, The MIT Press.

Ullah, S., Akhtar, P. and Zaefarian, G., 2018. Dealing with endogeneity bias: The generalized method of moments (GMM) for panel data. Ind. Mark. Manag., 71, 69-78. 
Ullah, S., Zaefarian, G. and Ullah, F., 2020. How to use instrumental variables in addressing endogeneity? A stepby-step procedure for non-specialists. Ind. Mark. Manag., Forthcoming.

Zhang, Y.J., 2011. The impact of financial development on carbon emissions: an empirical analysis in China. Energy Policy 39, 2197-2203.

Zhang, H., Kuuluvainen, J., Lin, Y., Gao, P., \& Yang, H. 2017. Cointegration in China's log import demand: Price endogeneity and structural change. J. For. Econ., 27, 99-109.

Zhu, H., Duan, L., Guo, Y., Yub, K., 2016. The effects of FDI, economic growth and energy consumption on carbon emissions in ASEAN-5: evidence from panel quantile regression. Econom. Model. 58, 237-248. 